\title{
Interfacial properties of Daqing crude oil-alkaline system
}

\author{
LIN Mei-qin ${ }^{1 *}$, XU Xue-qin ${ }^{1}$, LV Jing ${ }^{2}$, Zong Hua ${ }^{3}$, LI Ming-yuan ${ }^{1}$ and \\ DONG Zhao-xia ${ }^{1}$
}

${ }^{1}$ Enhanced Oil Recovery Research Center, China University of Petroleum, Beijing 102249, China

${ }^{2}$ Research Institute of Petroleum Exploration \& Development, PetroChina, Beijing 100083, China

${ }^{3}$ Shengli Engineering \& Consulting Co., Ltd., SINOPEC, Dongying, Shangdong 257026, China

(C) China University of Petroleum (Beijing) and Springer-Verlag Berlin Heidelberg 2011

\begin{abstract}
The oil/water interfacial properties of crude oil emulsions formed by alkaline/surfactant/ polymer (ASP) flooding in the Daqing Oilfield were investigated in this paper by the measurement of interfacial tension, interfacial shear viscosity and Zeta potential of the oil/water system. The result showed that both $\mathrm{NaOH}$ and $\mathrm{Na}_{2} \mathrm{CO}_{3}$ could react with acid substances in the crude oil to produce interfacially active components, which are adsorbed on the interfaces between the aqueous phase and oil phase, resulting in a decrease of the interfacial tension, negatively charging the surface of oil droplets, but making little change in the interfacial shear viscosity. For the same ionic strength of $\mathrm{NaOH}$ and $\mathrm{Na}_{2} \mathrm{CO}_{3}$, the interfacial tension of $\mathrm{NaOH}$ solution-crude oil system is lower, but the interfacial shear viscosity of $\mathrm{NaOH}$ solution-crude oil system is higher, than that of $\mathrm{Na}_{2} \mathrm{CO}_{3}$ solution-crude oil system. The negative value of the Zeta potential on the surface of the oil droplets is large. Accordingly, the $\mathrm{O} / \mathrm{W}$ emulsion of $\mathrm{NaOH}$ solution-crude oil system is more stable than that of $\mathrm{Na}_{2} \mathrm{CO}_{3}$ solution-crude oil system.
\end{abstract}

Key words: Alkali, interfacial tension, interfacial shear viscosity, Zeta potential, turbidity

\section{Introduction}

In recent years, alkali/surfactant/polymer (ASP) flooding has been used to enhance oil recovery in China (Shen and Yu, 2001; Wan, 1996). ASP flooding can significantly improve the oil recovery but the produced fluids form more stable oilin-water $(\mathrm{O} / \mathrm{W})$ emulsion than simple water flooding. As a result, the dehydration rate of the produced fluids by ASP flooding is low, resulting in high oil content in waste water and making waste water treatment more difficult (Deng et al, 2002; Zhang et al, 2006). Among the three components of ASP, alkali has a great effect on the emulsification of oil and stability of the emulsion. Alkali in ASP flooding could react with some crude oil components, forming soap with sodium ions (Lakatos-Szabo and Lakatos, 1999; Acevedo et al, 1999). This soap is surface-active and can emulsify crude oil to from a stable emulsion (Guo et al, 2006; Wu et al, 2001; Luo et al, 2003). The reaction between alkali and crude oil can generate both oil soluble surfactants and water soluble surfactants. It is easy for water-soluble surfactants to emulsify crude oil to $\mathrm{O} / \mathrm{W}$ emulsion, which made the produced fluids more stable and difficult to be treated. The stability of produced fluids is related to interfacial properties (Li et al, 2002; Dicharry et

*Corresponding author. email: linmq@cup.edu.cn

Received March 15, 2010 al, 2006; Opawale and Burgess, 1998), so this paper focuses on the effect of $\mathrm{NaOH}$, or $\mathrm{Na}_{2} \mathrm{CO}_{3}$, with Daqing crude oil on water/oil interfacial properties.

\section{Experimental}

\subsection{Materials}

The crude oil used in the experiment has an acid number of $0.05 \mathrm{mg}(\mathrm{KOH}) / \mathrm{g}$ (crude oil) and was provided by Daqing oilfield, Northeast China. The composition of synthesized Daqing oilfield formation water is listed in Table 1. NaCl, $\mathrm{NaOH}, \mathrm{Na}_{2} \mathrm{CO}_{3}, \mathrm{NaHCO}_{3}, \mathrm{CaCl}_{2}, \mathrm{MgSO}_{4}$ were all analytically pure. Kerosene used for preparing model oil was provided by Beijing Yanshan Petrochemical Co. Ltd., China. The kerosene was repeatedly purified with activated silica gel. After the adsorption treatment, the interfacial tension between kerosene and redistilled water is more than $48 \mathrm{mN} \cdot \mathrm{m}^{-1}$.

Table 1 Major ion composition of formation water from the Daqing oilfield

\begin{tabular}{ccccccccc}
\hline Ion & $\mathrm{Na}^{+}$ & $\mathrm{Ca}^{2+}$ & $\mathrm{Mg}^{2+}$ & $\mathrm{SO}_{4}{ }^{2-}$ & $\mathrm{Cl}^{-}$ & $\mathrm{CO}_{3}^{2-}$ & $\mathrm{HCO}_{3}^{-}$ & Salinity \\
\hline $\begin{array}{c}\text { Concentration } \\
\text { mg/L }\end{array}$ & 1686.89 & 0.72 & 0.83 & 0.68 & 1214.37 & 96.79 & 2196 & 5196.28 \\
\hline
\end{tabular}




\subsection{Measurement of interfacial tension}

The interfacial tension between model oil and aqueous alkali was measured at $30^{\circ} \mathrm{C}$ by the Wilhelmy method, using a Tensiometer DCAT-21 made by Dataphysics Instruments Ltd, Germany.

\subsection{Measurement of interfacial shear viscosity}

The interfacial shear viscosity between model oil and aqueous alkali was measured at $30{ }^{\circ} \mathrm{C}$ by biconical bob method, using a SVR·S interfacial viscoelastic meter (Kyowa Kagaku Co. Ltd., Japan).

\subsection{Zeta potential on the surface of oil droplets}

The Zeta potential on the surface of oil droplets in $\mathrm{O} /$ $\mathrm{W}$ emulsion was measured at $30{ }^{\circ} \mathrm{C}$ with a Zetasizer NanoZS and Zeta potentiometric analyzer made by Malvern Instruments Ltd. (United Kingdom).

\subsection{Measurement of emulsion stability}

The $\mathrm{O} / \mathrm{W}$ emulsions were prepared from the model oil and synthesized formation water (with a volume ratio of 1:4) in an emulsifier (IKA-18, Germany) and then stirred at 6,000 r/min for $5 \mathrm{~min}$. The relationship of turbidity vs. time was obtained at $25{ }^{\circ} \mathrm{C}$ with a Turb 550 turbidity meter made by WTW company (Germany) and the turbidity was used for judging the stability of the $\mathrm{O} / \mathrm{W}$ emulsion.

\section{Results and discussion}

\subsection{Effect of sodium hydroxide on interfacial properties}

\subsubsection{Effect of sodium hydroxide on interfacial tension}

Fig. 1 shows the relationship of interfacial tension vs. time between different mass concentrations of $\mathrm{NaOH}$ solution and $10 \%$ Daqing model oil. It can be seen that for a concentration of $\mathrm{NaOH}$ solution, the oil/water interfacial tension decreased gradually with time and tended to stabilize, and that with the increase of $\mathrm{NaOH}$ concentrations, the oil/water interfacial

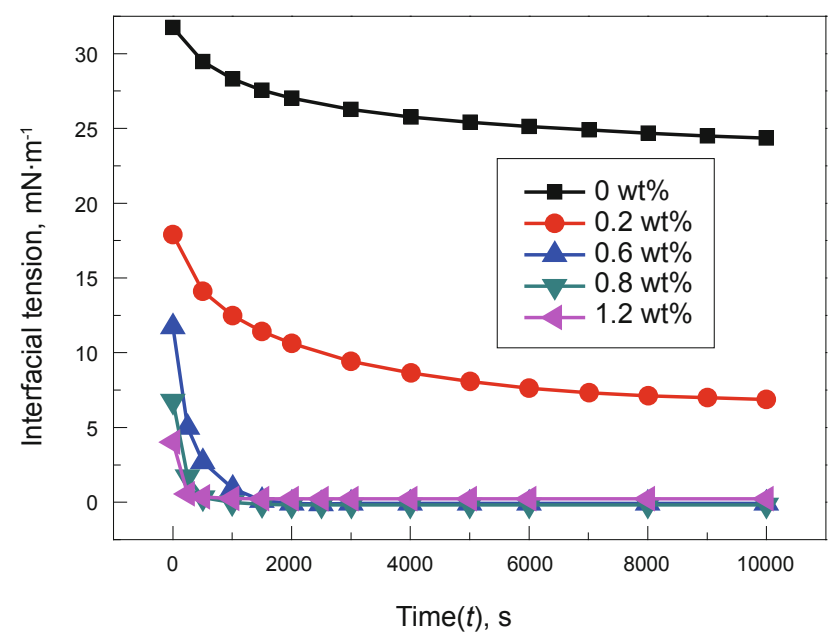

Fig. 1 Influence of $\mathrm{NaOH}$ concentration on the interfacial tension between model oil and water tension declined. At an $\mathrm{NaOH}$ concentration of $1.2 \mathrm{wt} \%$, the oil/water interfacial tension rose again because the ionic strength increased. The higher the $\mathrm{NaOH}$ concentrations, the shorter the time for $\mathrm{NaOH}$ solution-Daqing model oil system to reach stability. This is because with the increase of $\mathrm{NaOH}$ concentration and ionic strength, the diffusion rate of $\mathrm{NaOH}$ molecules and adsorption rate increases, and $\mathrm{NaOH}$ quickly reacts with acidic substances and esters in crude oil to generate interfacial surfactants. As a result, the oil/water interfacial tension declined and tended to stabilize quickly.

\subsubsection{Effect of sodium hydroxide on interfacial shear viscosity}

Fig. 2 shows the changes of interfacial shear viscosity of the $\mathrm{NaOH}$ solution (with different $\mathrm{NaOH}$ concentrations)/ model oil systems with shear rate. It is shown that the interfacial shear viscosities of the model oil/ $\mathrm{NaOH}$ solution system with different $\mathrm{NaOH}$ concentrations were all small and almost the same, indicating that the reaction between $\mathrm{NaOH}$ and Daqing model oil in a short time hardly influenced the oil/water interfacial shear viscosity.

Interfacially active agents stay on interface forming an interfacial film. The tighter and more intense the interfacial film, the larger the oil/water interfacial viscosity. The crude oil from Daqing oilfield is a paraffin-based oil with a content of asphaltene less than $1 \%$ and a content of saturates and aromatics more than $90 \%$, and has a small acid number. The interfacially active agents formed by oil and $\mathrm{NaOH}$ were absorbed on the oil-water interface as molecules. The intensity of the interfacial film was relatively weak. As a result, the interfacial shear viscosity was small.

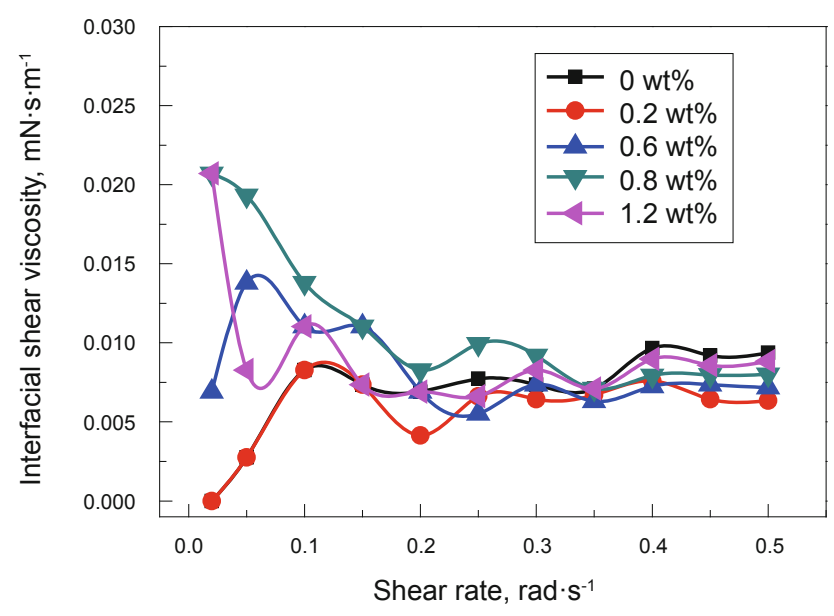

Fig. 2 Influence of $\mathrm{NaOH}$ concentration on the interfacial shear viscosity between model oil and water

\subsubsection{Effect of sodium hydroxide on Zeta potential}

Because of the limits of the Zeta potentiometric analyzer, the ionic strength in the measurement of Zeta potential could not exceed $0.3 \mathrm{~mol} / \mathrm{kg}$, the $\mathrm{NaOH}$ solution/ Daqing model oil system with different mass concentrations of $\mathrm{NaOH}$ was diluted two-fold with synthesized formation water after it was homogenized and kept for 5 hours. Fig. 3 shows the influence of $\mathrm{NaOH}$ concentration on the Zeta potential on the surface of oil droplets in $\mathrm{O} / \mathrm{W}$ emulsion. 


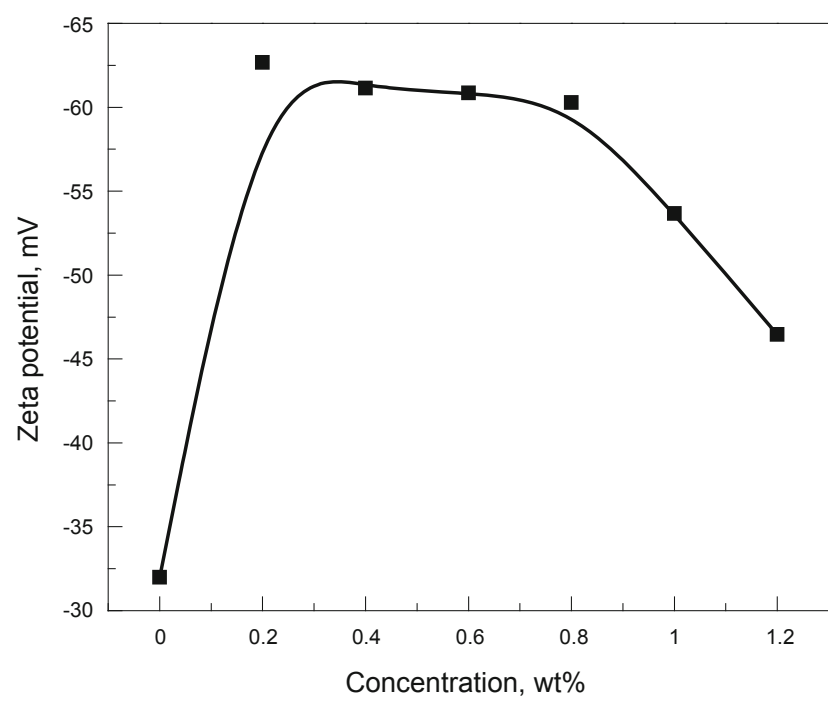

Fig. 3 Influence of $\mathrm{NaOH}$ concentration on the Zeta potential of $\mathrm{O} / \mathrm{W}$ emulsion

Fig. 3 shows that the absolute value of Zeta potential on the surface of oil droplets first increased and then declined with increasing concentrations of $\mathrm{NaOH}$. $\mathrm{NaOH}$ had two functions: firstly, as a strong alkali $\mathrm{NaOH}$ reacted with acidic components in the model oil and produced compounds with a high degree of ionization. In this process, the acidic components in the model oil were neutralized to salts, improving the degree of ionization and leading to the increase of the absolute value of Zeta potential; secondly, when the concentration of $\mathrm{NaOH}$ was high, the surplus $\mathrm{NaOH}$ played the role of an electrolyte, enhancing the ionic strength of the aqueous phase and hence leading to the compression of the electric double layer around the oil droplets. As a result, the absolute value of the Zeta potential on the surface of oil droplets decreased. The change of Zeta potential on the surface of oil droplets with the concentration of $\mathrm{NaOH}$ was the result of a combination of the two factors.

\subsection{Effect of sodium carbonate}

\subsubsection{Effect of $\mathrm{Na}_{2} \mathrm{CO}_{3}$ on interfacial tension}

Fig. 4 shows the interfacial tension between the $10 \%$ Daqing model oil and $\mathrm{Na}_{2} \mathrm{CO}_{3}$ solution with different $\mathrm{Na}_{2} \mathrm{CO}_{3}$ concentrations vs. reaction time. It is seen that the interfacial tension decreased gradually with an increase of $\mathrm{Na}_{2} \mathrm{CO}_{3}$ concentration. This is because with the increase of $\mathrm{Na}_{2} \mathrm{CO}_{3}$ concentration and ionic strength, the diffusion rate of $\mathrm{Na}_{2} \mathrm{CO}_{3}$ from water to interface and adsorption rate all increased. $\mathrm{Na}_{2} \mathrm{CO}_{3}$ reacted with acidic substances to generate interfacial surfactants. With more and more interfacial surfactants being produced, the interfacial tension first declined and then tended to stabilize.

Comparing Fig. 1 with Fig. 4, it is seen that the interfacially active agents generated by acidic components in crude oil and different alkaline substances had considerably different influences on the interfacial tension. At the same mass concentration of $\mathrm{Na}_{2} \mathrm{CO}_{3}$ solution and $\mathrm{NaOH}$ solution, the $\mathrm{NaOH}$ solution-Daqing model oil system had lower interfacial tension than $\mathrm{Na}_{2} \mathrm{CO}_{3}$ solution-Daqing model oil system, and the time to reach stable interfacial tension was shorter.

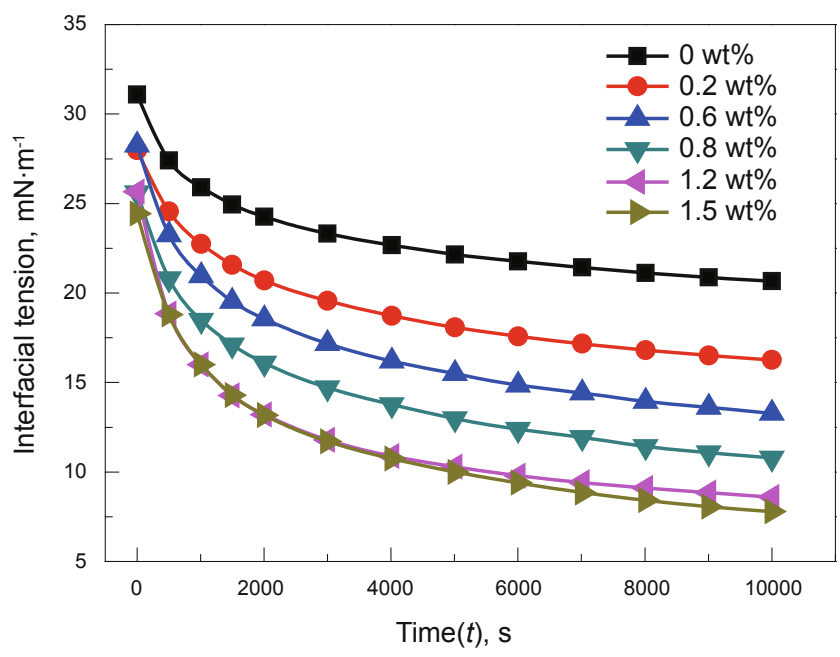

Fig. 4 Influence of $\mathrm{Na}_{2} \mathrm{CO}_{3}$ concentration on the interfacial tension between model oil and water

\subsubsection{Effect of $\mathrm{Na}_{2} \mathrm{CO}_{3}$ on interfacial shear viscosity}

Fig. 5 shows the interfacial shear viscosity of $\mathrm{Na}_{2} \mathrm{CO}_{3}$ solution-Daqing model oil system with different $\mathrm{Na}_{2} \mathrm{CO}_{3}$ concentrations vs. shear rate. It can be seen that $\mathrm{Na}_{2} \mathrm{CO}_{3}-$ Daqing model oil system had low interfacial shear viscosity. Comparing with Fig. 2, the difference of the interfacial shear viscosity between $\mathrm{NaOH}$ (strong alkali) solution-model oil system and $\mathrm{Na}_{2} \mathrm{CO}_{3}$ (weak alkali) solution-model oil system was not significant, indicating that the type and mass concentration of alkali had little influence on the formation of interfacial film and its strength.

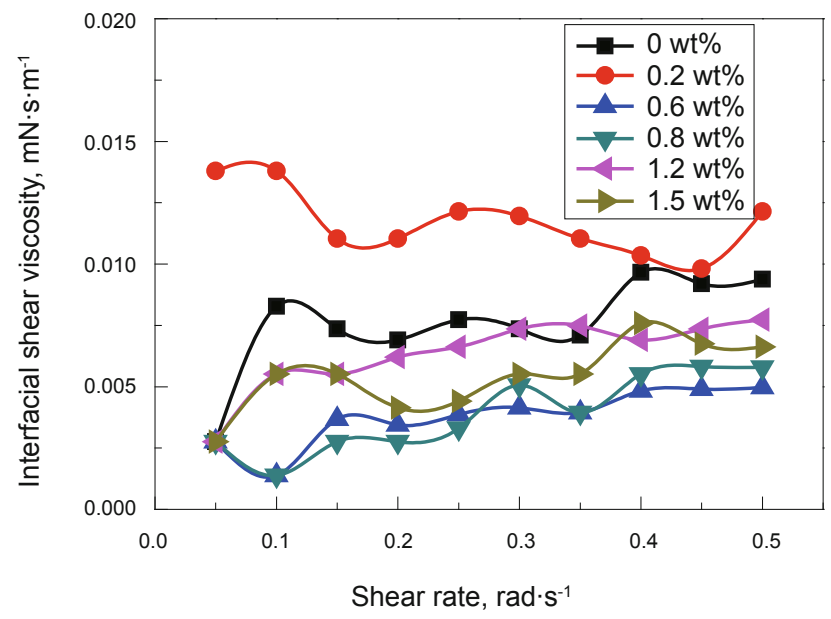

Fig. 5 Influence of $\mathrm{Na}_{2} \mathrm{CO}_{3}$ concentration on the interfacial shear viscosity between model oil and water

\subsubsection{Effect of $\mathrm{Na}_{2} \mathrm{CO}_{3}$ on Zeta potential}

The $\mathrm{Na}_{2} \mathrm{CO}_{3}$ solution-Daqing model oil system with different $\mathrm{Na}_{2} \mathrm{CO}_{3}$ mass concentrations was diluted onefold using synthesized formation water which had already been emulsified and kept for 5 hours. Fig. 6 shows the Zeta potential on the surface of oil droplets of the system. 
It is shown that with increasing $\mathrm{Na}_{2} \mathrm{CO}_{3}$ concentration, the absolute value of the Zeta potential on the surface of oil droplets first increased and then decreased. Comparing Fig. 3 with Fig. 6, at the same alkali concentration, the $\mathrm{Na}_{2} \mathrm{CO}_{3}$ solution-model oil system had a lower Zeta potential than the $\mathrm{NaOH}$ solution-model oil system. The reason is that $\mathrm{Na}_{2} \mathrm{CO}_{3}$ is weak alkali and could only react with acidic components of crude oil, but not with esters. Hence little interfacially active agents were produced and only a small amount of electric charge was adsorbed on the surface of oil droplets, resulting in the $\mathrm{Na}_{2} \mathrm{CO}_{3}$ solution-model oil system having a smaller absolute value of the Zeta potential than the $\mathrm{NaOH}$ solutionmodel oil system.

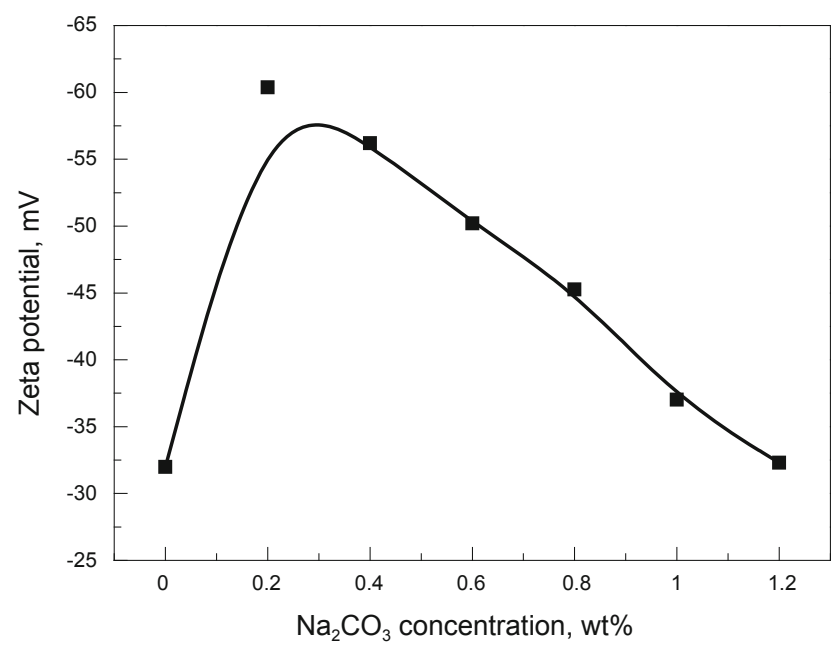

Fig. 6 Influence of $\mathrm{Na}_{2} \mathrm{CO}_{3}$ concentration on the Zeta potential of $\mathrm{O} / \mathrm{W}$ emulsion

\subsection{Oil/water interfacial properties at the same ionic strength of $\mathrm{NaOH}$ and $\mathrm{Na}_{2} \mathrm{CO}_{3}$}

Even though the mass concentration of $\mathrm{NaOH}$ and $\mathrm{Na}_{2} \mathrm{CO}_{3}$ was the same, the ionic strength of the two system was different, which would influence the interfacial properties between oil and water. At the same ionic strength of 0.375 $\mathrm{mol} / \mathrm{kg}$, the interfacial properties between Daqing model oil and $\mathrm{NaOH}$ or $\mathrm{Na}_{2} \mathrm{CO}_{3}$ aqueous solution were investigated.

\subsubsection{Interfacial tension at the same ionic strength}

Fig. 7 shows the relationship of interfacial tension vs. reaction time for $\mathrm{NaOH}$ solution-model oil and $\mathrm{Na}_{2} \mathrm{CO}_{3}$ solution-model oil systems, at the same ionic strength.

It can be seen that at the same ionic strength, the $\mathrm{NaOH}$ solution-model oil system had lower interfacial tension than the $\mathrm{Na}_{2} \mathrm{CO}_{3}$ solution-model oil system. Moreover, it took a shorter time for the $\mathrm{NaOH}$ solution-model oil system to reach a stable interfacial tension than the $\mathrm{Na}_{2} \mathrm{CO}_{3}$ solution-model oil system. The reason is that the reaction rate of $\mathrm{NaOH}$ (as a strong alkali) with the acidic components in Daqing model oil was fast, and a large amount of interfacially active agents were generated and adsorbed on oil/water interface and reach a stable state sooner. As a result, the interfacial tension between water and oil decreased steeply and became stable soon. The reaction rate of $\mathrm{Na}_{2} \mathrm{CO}_{3}$ (as a weak alkali) with the

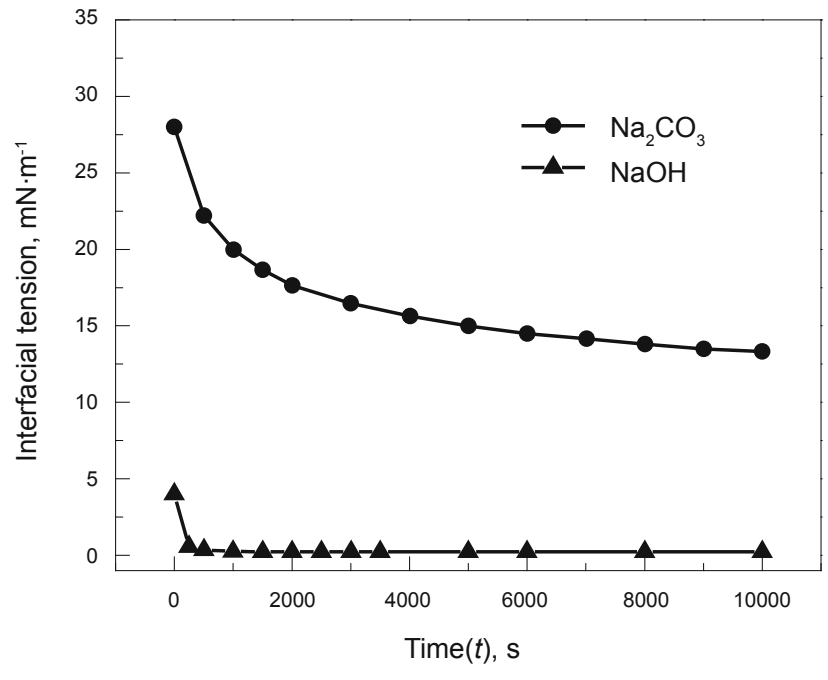

Fig. 7 Interfacial tension between $\mathrm{NaOH}$ or $\mathrm{Na}_{2} \mathrm{CO}_{3}$ solution and Daqing model oil

acidic components in Daqing model oil was slow. Therefore, a small amount of interfacially active agents were generated. The $\mathrm{Na}_{2} \mathrm{CO}_{3}$ solution-Daqing model oil system had a higher interfacial tension than $\mathrm{NaOH}$ solution-model oil system, and it took longer time for the $\mathrm{Na}_{2} \mathrm{CO}_{3}$ solution-Daqing model oil system to reach a stable state.

All the results showed that alkali could react with crude oil to produce interfacially active substances, which were adsorbed on the oil/water interface and lower the oil/water interfacial tension in a short time. At the same ionic strength, the strong alkali-Daqing model oil system reacted more quickly. As a result, more interfacially active substances were formed. The oil/water interfacial tension decreased steeply and reach a stable state sooner.

\subsubsection{Interfacial shear viscosity at the same ionic strength}

Fig. 8 shows the interfacial shear viscosity of $\mathrm{NaOH}$ solution-model oil system and $\mathrm{Na}_{2} \mathrm{CO}_{3}$ solution-model oil system with the shear rate, at the same ionic strength.

It is shown that at the same ionic strength, the $\mathrm{NaOH}$ solution-model oil system had a higher interfacial shear

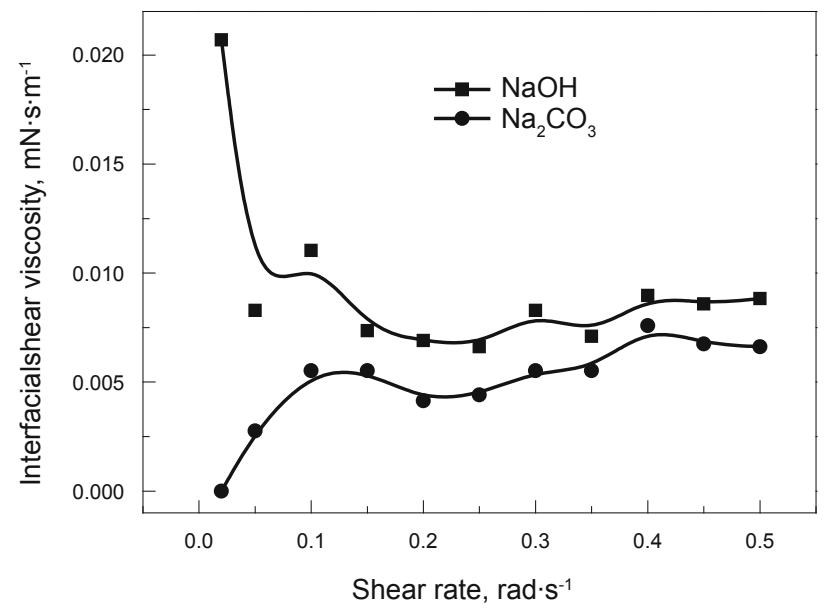

Fig. 8 Interfacial shear viscosity between $\mathrm{NaOH}$ or $\mathrm{Na}_{2} \mathrm{CO}_{3}$ solution and Daqing model oil 
viscosity than the $\mathrm{Na}_{2} \mathrm{CO}_{3}$ solution-model oil system. This is because $\mathrm{Na}_{2} \mathrm{CO}_{3}$ could only react with small acidic molecules in the oil. But for strong alkali $\mathrm{NaOH}$, they could react with not only small molecules but also long-chain macromolecules, resulting in that more interfacially active substances were produced and adsorbed on the interface to form strong films.

3.3.3 Zeta potential on the surface of oil droplets at the same ionic strength

At the same ionic strength of $0.375 \mathrm{~mol} / \mathrm{kg}$, the Zeta potentials on the surface of oil droplets in $\mathrm{NaOH}$, or $\mathrm{Na}_{2} \mathrm{CO}_{3}$, solution-Daqing crude oil systems are shown in Table 2. It can be seen that the absolute value of Zeta potential on the oil droplets' surface in the $\mathrm{NaOH}$ solution-model oil system was larger than that in the $\mathrm{Na}_{2} \mathrm{CO}_{3}$ solution-model oil system. The main reason was that the strong alkali reacted with acidic substances of the crude oil, making the adsorption and ionization on the interface easy, and resulting in the absolute value of Zeta potential on the surface of oil droplets become larger.

Table 2 The Zeta potential of $\mathrm{O} / \mathrm{W}$ emulsion formed by $\mathrm{NaOH}$ or $\mathrm{Na}_{2} \mathrm{CO}_{3}$ solution with Daqing model oil

\begin{tabular}{ccc}
\hline Alkali & $\mathrm{NaOH}$ & $\mathrm{Na}_{2} \mathrm{CO}_{3}$ \\
\hline =HMB RWQWOP 9 & $\square \square$ & $\square \square \quad \square$ \\
\hline
\end{tabular}

\subsubsection{Stability of emulsion at the same ionic strength}

Fig. 9 shows the turbidity of the emulsions, formed by $10 \%$ Daqing model oil in $\mathrm{NaOH}$ or $\mathrm{Na}_{2} \mathrm{CO}_{3}$ solution, with time, with the same ionic strength. It is seen the emulsion formed by $\mathrm{NaOH}$ solution and model oil had a higher turbidity than that formed by $\mathrm{Na}_{2} \mathrm{CO}_{3}$ solution-model oil, indicating that the $\mathrm{O} / \mathrm{W}$ emulsion formed by strong alkali $\mathrm{NaOH}$ solution and model oil was more stable. This is because that strong alkali $\mathrm{NaOH}$ reacted with model oil and produced more interfacially active substances being adsorbed on oil/water interface, leading to a steep decrease in the oil/ water interfacial tension (see Fig. 7), an increase of interfacial shear viscosity (see Fig. 8), and a rise in negative value of

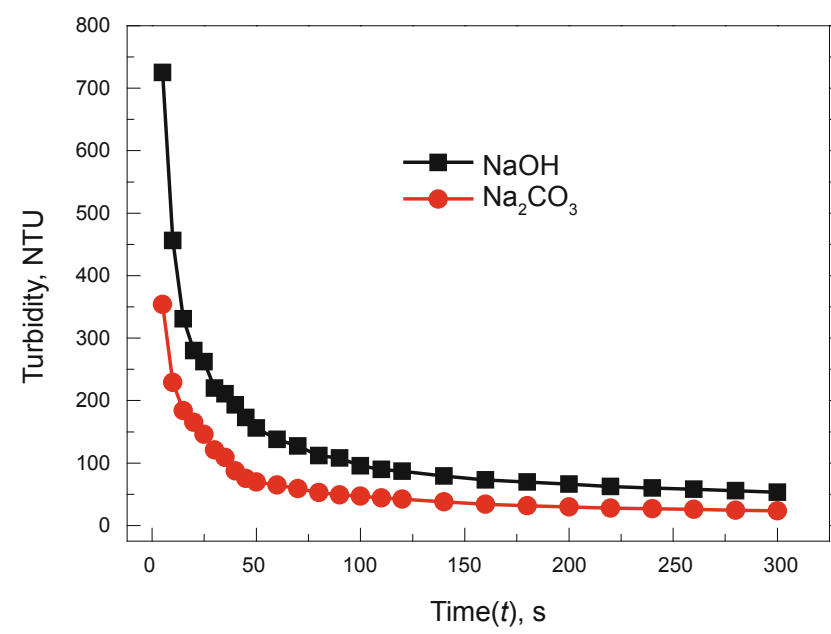

Fig. 9 The turbidity of $\mathrm{O} / \mathrm{W}$ emulsion formed by $\mathrm{NaOH}$ or $\mathrm{Na}_{2} \mathrm{CO}_{3}$ solution and model oil vs. time
Zeta potential on the surface of the oil droplets (see Table 2). Under the condition of constant interfacial area, the interfacial energy decreased with the decrease of oil/water interfacial tension. The increase of interfacial shear viscosity made the oil/water interfacial film stronger, so it was more difficult for oil droplets in the emulsions to aggregate. The increase of the negative value of Zeta potential made the electrostatic repulsive force between the oil droplets in the emulsion stronger. The cooperation of the above three actions made $\mathrm{O} / \mathrm{W}$ emulsion formed by $\mathrm{NaOH}$ solution-model oil system more stable than that by $\mathrm{Na}_{2} \mathrm{CO}_{3}$ solution-model oil system.

\section{Conclusions}

(1) $\mathrm{NaOH}$ or $\mathrm{Na}_{2} \mathrm{CO}_{3}$ reacted with acidic components in Daqing oil and produced interfacially active agents, which could adsorb on the interface between oil and water, then reduced the interfacial tension. With an increase of $\mathrm{NaOH}$ and $\mathrm{Na}_{2} \mathrm{CO}_{3}$ mass concentrations, more interfacially active components were generated. As a result, the oil/ water interfacial tension decreased gradually. Meanwhile, the absolute value of the Zeta potential on the oil droplets decreased gradually because of increase in the ionic strength of the aqueous phase.

(2) $\mathrm{NaOH}$, as a strong alkali, compared with $\mathrm{Na}_{2} \mathrm{CO}_{3}$, with the same ionic strength, could react with neutral and acidic substances, esters in the crude oil quickly. More interfacially active agents produced by the reaction led to a decrease in the interfacial tension of the $\mathrm{NaOH}$ solution-Daqing crude oil system.

\section{Acknowledgements}

This work was supported by the National Basic Research Program of China (973 Program) (Grant No. 2006CB705805) and the National Key Scientific and Technological Project (863 Project) (Grant No. 2008ZX05011).

\section{References}

Acevedo S, Ranaudo M A, Escobar G and Gutiérrez X. Dynamic interfacial tension measurement of heavy crude oil-alkaline systems. Fuel. 1999. 78: 309-317

Deng S B, Bai R B, Chen J P, et al. Effects of alkaline/surfactant/ polymer on stability of oil droplets in produced water from ASP flooding. Colloids and Surfaces. 2002. 211: 275-284

Dicharry C, Arla D, Sinquin A, et al. Stability of water/crude oil emulsions based on interfacial dilatational rheology. Journal of Colloid and Interface Science. 2006. 297(2): 785-791

Guo J X, Liu Q, Li M Y, et al. The effect of alkali on crude oil/water interfacial properties and the stability of crude oil emulsions. Colloids and Surfaces. 2006. 273: 213-218

Lakatos-Szabo J and Lakatos I. Effect of alkaline materials on interfacial rheological properties of oil-water system. Colloid Polym Sci. 1999. 277: 41-47

Li M Y, Xu M J, Ma Y, et al. Interfacial film properties of asphaltenes and resins. Fuel. 2002. 81: 1847-1853

Luo X H, Lin M Q, Wu Z L, et al. Emulsification of crude oil with alkaline-surfactant-polymer flooding system. Fine Chemicals. 2003. (12): 721-741 (in Chinese)

Opawale F O and Burgess D J. Influence of interfacial properties of 
lipophilic surfactants on water-in-oil emulsion stability. J. Colloid Int. Sci. 1998. 197: 142-150

Shen P P and Yu J Y. Basic Research on Enhanced Oil Recovery. Beijing: Petroleum Industry Press. 2001 (in Chinese)

Wan D M. Pilot tests of alkaline/surfactant/polymer flooding in the Daqing oil field. SPE 36748. 1996. 229-243

Wu D, Meng X C, Zhang R Q, et al. Stability and chemical treatment of Daqing Oilfield ASP flooding produced water. Fine Chemicals. 2001. 18(2): 86-88 (in Chinese)

Zhang R Q, Liang C H and Wu D. Characterization and demulsification of produced liquid from weak base ASP flooding. Colloids and Surface A: Physicochem. Eng. Aspects. 2006. 290: 164-171

(Edited by Zhu Xiuqin) 